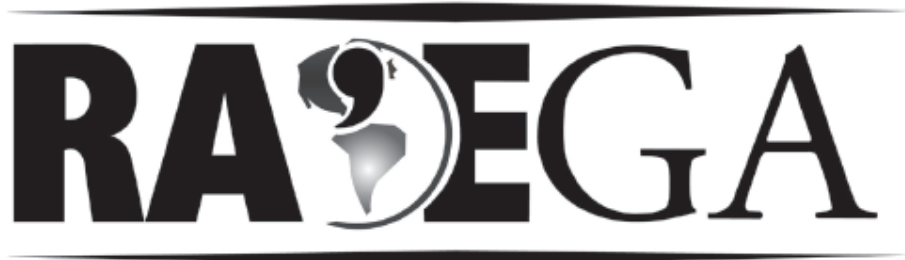

O ESPAÇO GEOGRÁFICO EM ANÁLISE

\title{
ALGUMAS CONSIDERAÇÕES SOBRE A VALIDADE DA TEORIA DO DESENVOLVIMENTO DESIGUAL DE NEIL SMITH
}

\section{SOME CONSIDERATIONS ON THE WORTHINESS OF THE NEIL SMITH'S UNEVEN DEVELOPMENT THEORY}

\author{
Elias Coimbra da Silva ${ }^{1}$
}

\begin{abstract}
Resumo
Uma vez que o Modo de Produção Capitalista tem se refeito a partir do caos que ele mesmo produz, é necessário entendermos como, atualmente, essa lógica contraditória tem operado. É necessário, igualmente, entendermos como o espaço participa dessa mesma lógica. Entretanto, qual espaço referimos, quando dizemos isso? Ou melhor, qual a natureza desse espaço que serve tanto como fator de produção, mercadoria e lugar? Numa análise do livro "Desenvolvimento Desigual: Natureza, Capital e a Produção do Espaço", de Neil Smith, tentar-se-á esclarecer essas assertivas.
\end{abstract}

Palavras-chave: Desenvolvimento Desigual; Espaço; Natureza; Capitalismo; Valor.

\begin{abstract}
Inasmuch as the Capitalist Model of Production has been remaking itself from the chaos that it produces, it is necessary understand as at the present time that contradictory logic has been operating. It is necessary, equally, we understand as the space participates in that same logic. However, which space did the one refer when do we say that? Or better, which the nature of that space that serves as much as factor of production, commodity and place? In an analysis of the book "Uneven Development: Nature, Capital, and the Production of Space" of Neil Smith, we will try to explain those assertive ones.
\end{abstract}

Key-words: Uneven Development; Space; Nature; Capitalism; Value.

\footnotetext{
${ }^{1}$ Mestre em Geografia pela Univ. Fed. Grande Dourados / MS, doutorando em História Social pela Univ. Fed. Uberlândia / MG. E.mail: coimbraelias@hotmail.com
} 


\section{Introdução}

Desde que Marx escreveu sua obra-prima, "O Capital", muitos outros textos acerca dessa obra foram produzidos. Alguns visavam "destruir" os argumentos contidos nela, sobretudo pelo seu caráter politicamente engajado muitos foram e são os inimigos de Marx e dos pensadores que têm criticado o status quo da sociedade - e outros visavam reproduzir tais argumentos (no que se forjou a alcunha de marxistas para esses últimos textos). Eventualmente, algum teórico se propunha a tarefa - talvez mais arriscada - de ampliar o escopo de "O Capital", no que esse livro faltou discorrer, quando não, ressignificá-lo com alguma interpretação inusitada; tais são, respectivamente, os exemplos de Karl Kautsky em "A Questão Agrária" (ABRAMOVAY, 2007) e Louis Althusser em "Ler o Capital” (DOSSE, 1993, p. 326).

Neil Smith, quando escreveu o livro "Desenvolvimento Desigual” (1988), tinha, certamente, intenções análogas às dos autores citados, sobretudo às de Kautsky - posto que na sua exposição, à luz da teoria marxista, dos elementos constituintes da economia rural, lança luz a um tema não explorado em "O Capital". Assim, N. Smith pretendia refletir sobre o conceito de Espaço conceito não explicitamente abordado por Marx - sem distanciar-se da teoria econômica marxiana, ou melhor, pretendia refletir sobre a produção do Espaço, sob a ótica do Materialismo Histórico e Dialético.

De modo geral, dois são os argumentos que sustentam a referida obra de N. Smith, sendo que o primeiro afirma que o homem produz a natureza para além da produção do próprio espaço. Para tal assertiva ser possível, o autor intenta demonstrar que a realidade (do ponto de vista do materialismo, do ateísmo, etc.) é, ao menos na época avançada em que vivemos, absolutamente produzida pelo homem. Em outras palavras, N. Smith faz equivalerem Natureza e Realidade.

O segundo argumento, enfim, propõe que o Sistema Capitalista produz o espaço de maneira desigual. Essa maneira desigual dá-se por meio do vaivém do capital: ele gera a escassez num certo espaço pari passu a uma opulência em outro, sendo que essa mobilidade - que é o fixo espacial e condição sine 
qua non do próprio Capitalismo - é viabilizada pela transformação da capital constante em variável e vice-versa.

No presente trabalho, buscar-se-á analisar ambos os argumentos e, além disso, serão feitas algumas críticas a respeito dos mesmos, tendo por base, sobretudo, a Sociologia e a Filosofia (em seus autores). Esse procedimento se deve à minha convicção ${ }^{2}$, a qual se filia à de tantos outros leitores de Ciências Humanas, e mesmo de certos autores que assim têm indicado, ao longo do Século $\mathrm{XX}$, de que a da sociedade é algo bem mais complexo do que meras considerações economicistas podem dar conta.

\section{O Homem é o produtor do meio}

Uma das propostas de N. Smith é exatamente debater alguns conceitos geográficos, como espaço e natureza, por exemplo, para "interrogar mais incisivamente a realidade em que vivemos" (SMITH, 1988, p. 7). Assim, a primeira parte do referido trabalho, representada pelos três capítulos iniciais ("A Ideologia da Natureza”, "A Produção da Natureza” e "A Produção do Espaço") não apresenta, a rigor, continuidade lógica na segunda parte (do mesmo livro de N. Smith). Em certo sentido, é o mesmo procedimento realizado no presente artigo (este: "Algumas considerações sobre a validade da teoria do Desenvolvimento Desigual"): inicialmente analisar-se-á a primeira parte do livro de Smith e, posteriormente, a segunda parte deste livro. Com isso pretende-se apresentar uma leitura crítica da obra, sem preocupações com uma solução de continuidade, ou melhor, com uma explanação cumulativa.

De acordo com o que está escrito na introdução deste texto (o presente), o primeiro argumento de N. Smith é aquele segundo o qual o homem produz a natureza. Neste momento, duas perguntas já se tornam prementes. Primeira: 0 que o autor entende por "produzir"? Segunda: o que ele entende por

\footnotetext{
2 Essa "declaração" de intenções é uma dívida minha para com a Historiografia. Ela me ensinou que, em Ciências Humanas, o rigor científico deve-se à explicitação do sujeito (e perspectiva) e não ao seu alijamento (RÜSEN, 2010, p. 113).
} 
"natureza"? Premência justificada, uma vez que tratam-se de conceitos polissêmicos, como qualquer outro em Ciências Humanas ${ }^{3}$.

Para responder à primeira pergunta, N. Smith vai do abstrato ao concreto - seguindo a metodologia do próprio Marx ${ }^{4}$ - e, a princípio, explicanos o que é a produção de um modo geral, para Marx: "Pela sua atividade" [qual seja: o trabalho) ", o homem modifica as formas das matérias naturais, de modo a torná-las úteis para ele" (SMITH, 1988, p. 71). Na seqüência, chegando ao concreto, N. Smith nos explica que a natureza é o mundo em que o homem vive: "O ser humano tem produzido tudo o que seja natural, tornando as coisas acessíveis para ele" (Ibidem, p. 97). A oração inteira, que expressa (até agora) o argumento de N. Smith, seria então: o trabalho humano transforma a matériaprima, transformando-a em utensílios.

Assim colocada, a idéia acima proposta, é praticamente um truísmo. Porém, ao que nos chama a atenção, N. Smith, é para o fato de que:

Com a produção para a troca, a produção da natureza ocorre em escala ampliada. Os seres humanos não produzem somente a natureza imediata de sua existência, mas produzem toda a textura social de sua existência. Desenvolvem uma diferenciação complexa na relação com a natureza, uma natureza social diferenciada, obedecendo o gênero e classe de atividade manual e mental, atividades de produção e distribuição e assim por diante. (SMITH, 1988, p. 82)

Ou seja, a partir do momento em que o trabalho humano gera o valorde-troca e não somente o valor-de-uso, ou simplesmente: a partir do momento em que existe (estruturalmente) um excedente, surgem estamentos sociais cuja função é administrá-lo (o excedente). A tais classes correspondem instituições sociais e divisões no espaço, específicas - divisões estas tanto mais pronunciadas quanto mais urbanizada for a sociedade considerada -, onde parte do excedente será administrado. Temos, então, uma situação nova, onde o trabalho ampliou o mundo natural com parcelas absolutamente sociais. Portanto temos o homem produzindo a natureza (pelo menos uma secção

\footnotetext{
${ }^{3}$ Há quem prefira diferir entre Definições e Noções, aplicando às humanidades, preferencialmente, o último termo.

${ }^{4}$ Grundrisse, p. 85, numa edição de Londres, 1973 (conforme a "Bibliografia" do livro de SMITH, 1988).
} 
dela). Esses dois termos: mundo, natureza (aos quais é lícito somarmos: "realidade") são problemáticos, pois se referem basicamente ao mesmo objeto, mas sob pontos de vista diferentes, em função da história das idéias:

Como foi anteriormente observado, a distinção entre 'mundo' e 'natureza' é uma distinção relativamente recente na conceptualidade e na terminologia filosóficas. Tendo recebido um estatuto crítico em Kant, ela fixou-se na sua significação atual a partir das análises de E. Husserl e M. Heidegger, passando então 'mundo' a ser empregado como noção fenomenológica e 'natureza' como noção científica, no sentido das ciências empírico-formais. (VAZ, 1992, p. 24)

De qualquer forma, a proposição de $\mathrm{N}$. Smith parece correta reconheçamos! - e, ainda assim, contêm alguns equívocos. Na maior parte contra a Escola de Frankfurt ${ }^{5}$ é que se originam tais equívocos, ou seja, na crítica infundada contra teorias propostas por ela. Quando, por exemplo, na página 65, N. Smith (1988) nos diz:

Enquanto o argumento da dominação da natureza sugere um futuro sombrio, unidimensional e livre de contradições, a idéia de produção da natureza sugere um futuro histórico que está ainda para ser determinado pelos eventos e pelas forças políticas e não pela necessidade técnica.

Fica claro que ele propõe que são, os dois processos (a dominação e a produção), absolutamente distintos, mas, logo depois, cita uma passagem na qual Marx afirma que a Humanidade é o sujeito em relação ao qual a natureza é objeto (SMITH, 1988, p. 70). Ora, não é outro o posicionamento tradicional burguês, sobre a relação homem/natureza. N. Smith, na vontade de defender seu posicionamento ideológico, acaba, injustamente, criticando a Escola de Frankfurt (como um todo) e imputa a ela exatamente uma falha de sua própria teoria (marxista), qual seja a separação entre o homem e a natureza. Marcuse, ao contrário, em seu "Der eindimensionale Mensch" ("O ser humano

\footnotetext{
5 "Fundado em 1924, o Instituto de Pesquisas Sociais de Frankfurt, do qual a Revista de Pesquisa Social (Zeitschrift für Sozialforschung) era porta-voz, foi obrigado, com a ascensão ao poder na Alemanha do Nacional-socialismo, 1933, a transferir-se para Genebra, depois para Paris e, finalmente, para Nova lorque." (ARANTES, 1980, p. VI).
} 
unidimensional") percebe que a relação sujeito/objeto do homem com a natureza é uma função da relação sujeito/objeto do homem para com o próprio homem, de forma que essas relações são historicamente produzidas e não: necessárias (HABERMAS, 1980, p. 316 e 317). É justamente o que a idéia de produção da natureza sugere (como se lê na citação, acima, citação da p. 65 do livro de Smith).

Temos uma passagem do mesmo N. Smith, onde ele diz, rigorosamente, o que disse Marcuse (embora critique esse mesmo Marcuse por isso, dizendoo "sombrio e unidimensional"):

Por outro lado, esse controle aumentado é necessariamente um controle social, e embora ele assessore a emancipação da sociedade humana como um todo em face da natureza, ele também favorece o desenvolvimento da diferenciação interna da sociedade e a escravidão de uma grande parte da população. (SMITH, 1988, p. 76)

Ao longo da História outros autores perceberam que o argumento da dominação da natureza, argumento esse, aliás, que nunca fora exclusividade de Marcuse, não é nem determinista e nem livre de contradições, como quer $\mathrm{N}$. Smith. Por exemplo, Porto Gonçalves, nos fala: "Separar o homem da natureza é, portanto, uma forma de subordiná-los ao capital." (GONÇALVES, 1998, p. 116). Mesmo o poeta e visionário William Blake - tão admirado na historiografia marxista inglesa ${ }^{6}$ - lá no Séc. XVIII, já vislumbrava essa proposição:

The ancient Poets animated all sensible objects with Gods or Geniuses calling them by the names and adorning the with the properties of woods, rivers, mountains, lakes, cities, nations, and whatever their enlarged \& numerous senses could percieve. / And particularly they studied the genius of each city \& country, placing it under its mental deity. / Till a system was formed, wich some took advantage of \& enslav'd the vulgar by attempting to realize or abstract the mental deities from their objects: thus began Priesthood. ${ }^{7}$ (BLAKE, 2004, p. 211)

\footnotetext{
${ }^{6}$ Mormente pela atenção que a esse poeta foi dedicada, por parte de Edward P. Thompson (vide: THOMPSON, E. P. Apocalisse e rivoluzione: William Blake e la legge morale. Milano: Raffaello Cortina Editore, 1996).

7 "Os poetas dos primitivos animaram todos os objetos sensíveis com Deuses ou Gênios chamando-os pelos nomes e adornando-os com as propriedades de madeiras, rios, montanhas, lagos, cidades, nações e quaisquer outras que os seus sentidos dilatados e numerosos poderiam perceber. / $\mathrm{E}$, particularmente, estudaram o gênio de cada cidade e país, colocando-os sob uma deidade mental particular. / Até que um
} 
A dominação da natureza não é uma proposição contraditória à produção da natureza (como se lê na citação da p. 65 do livro de Smith); na realidade, elas são complementares. Para entendermos como são complementares, é necessário fazer alusão à seguinte passagem de "A Construção Social da Realidade": "A sociedade é um produto humano. A sociedade é uma realidade objetiva. O homem é um produto social. Torna-se desde já evidente que qualquer análise do mundo social que deixe de lado algum destes três momentos será uma análise distorcida." (BERGER \& LUCKMANN, 1974, p. 87-88). São os três momentos da dialética hegeliana (utilizada no materialismo histórico), ou seja, tese, antítese e síntese. A reificação (Verdinglichung), que encontramos na Escola de Chicago, por exemplo, é a negação do primeiro momento, pois parte já da objetividade da sociedade.

A reificação da sociedade (ou da natureza, nas palavras de N. Smith) só é possível porque o homem, primeiro, produziu a sociedade. Por outro lado, tomada como coisa, a sociedade pode ser possuída, tum demum, como um excedente. Aos que a possuem (e que não a produzem), ou seja, para a classe capitalista, ela é um valor-de-troca, enquanto que para o produtor, ela é um valor-de-uso; além disso, a sociedade (ou a natureza, se preferirem) também pode ser uma propriedade privada e um meio de produção. Vemos assim que o problema da propalada contradição entre as proposições de dominação da natureza e produção da natureza, é, na verdade, fruto da complexidade da questão; que só pode ser resolvida dialeticamente. De um lado, o ponto de vista burguês propugna a favor da dominação da natureza (sem o homem); e de outro lado, o ponto de vista de N. Smith propugna a favor da produção da mesma natureza (mas sem o homem também ${ }^{8}$ ). Faltou, para Smith, combinar as duas posições: dominação/produção; reconhecendo, portanto, que existem classes sociais e que elas possuem mundos (naturezas) diferentes.

Outro exemplo de falha cometida por N. Smith está patente na passagem extraída de "Ideologia Alemã":

sistema foi formado, sistema sob o qual alguns se aproveitaram para escravizar a plebe, lançando mão das deidades mentais dos objetos: assim começou o Sacerdócio". [Trad. do autor] 
[...] essa atividade, esse trabalho, essa criação material incessante dos homens, essa produção é a base de todo o mundo sensível tal como hoje existe, a tal ponto que se o interrompêssemos apenas por um ano, Feuerbach não só encontraria enormes modificações no mundo material como até lamentaria a perda de todo o mundo humano e da sua própria faculdade de contemplação, ou mesmo da sua própria existência. (MARX \& ENGELS ${ }^{9}$; apud: SMITH, 1988, p. 71)

Vê-se que a produção humana é posta na base de todos os fenômenos (pela referência: "todo o mundo sensível"); seria uma nova forma de solipsismo? E esse argumento é complementado pela assertiva segundo a qual, "sem trabalho não haveria vida" (MARX'10; apud: SMITH, 1988, p. 71). Mas, se o trabalho é exclusivamente humano, como se poderia imaginar que a vida (biologicamente falando) também o é? Todavia, Marx fala da vida humana e vida humana enquanto vida social e não do ponto de vista da Antropologia Física - embora, nessa ciência mesmo, a distinção entre o que é "natural" e o que é "cultural", no homem, desde os primeiros hominídeos, não está resolvida completamente.

Nesse caso, voltamos ao solipsismo - seria ele um cogito ergo sum, em que não nos colocaríamos mais a questão da possibilidade de duvidarmos se existimos, mas sim, a questão da própria existência física, enquanto um conceito filosófico? Neil Smith, simplesmente, extraiu do (brilhante) parágrafo do texto marxiano-engelsiano, uma porção que o interessava e deu uma interpretação simplista da idéia.

Enfim, o homem produz seu mundo (sua natureza, sua sociedade etc), sem que "produza", com o mesmo mecanismo, seu ente biológico. Esse mesmo ente está condicionado por circunstâncias independentes da humanidade do homem, ou, dito de outra forma: antes do homem "ser humano", ele já era esse ente e poderia muito bem continuar o sendo, mesmo que jamais viesse a se humanizar (ou, humanizasse-se de uma forma diversa e a qual, olhando de fora, talvez, um pensador rigorosamente "humano" de uma

\footnotetext{
${ }^{8}$ O homem, neste caso, é uma abstração: o Ser Humano, abstração iluminista; portanto burguesa. Faltou Smith "situar" esse Homem, ou melhor, explicitar de qual(is) homem(ns) ele se refere.

${ }_{9}^{9}$ German ideology, p. 63 [sic]. Neil Smith não especifica qual a edição referida.

${ }^{10}$ MARX, K. Capital, 3 volumes (Nova lorque, 1967), pp. 42-3, 71.
} 
civilização inexistente, viesse a considerar inumana). No outro plano - não exatamente mais elevado - ele produz seu mundo (social) e a si mesmo, enquanto "homem ereto", "homem sábio" e "animal social"11.

\section{A produção desigual do espaço}

Dando seguimento ao que foi proposto, abordemos agora o segundo argumento de N. Smith, comecemos com sua definição de Espaço Geográfico, para - e como decorrência dessa definição - voltarmos à idéia inicial de produção do espaço.

Seguiremos a argumentação do autor e, portanto, o espaço será pensado como relativo e concreto, para os fins aqui buscados. Isso equivale dizer que não se sabe o suficiente sobre ele a ponto de podermos levar às últimas conseqüências essas considerações; e não se sabe o suficiente, por ser (o espaço) um dos conceitos mais controversos de que se tem nota nas Humanidades. Por isso, consideremos o Espaço Geográfico como relativo e concreto, por ser essa apenas outra teoria (do Smith), quo nomine; e reflitamos sobre tal.

O autor escreve:

Enquanto o espaço e a matéria permaneceram, de algum modo, confundidos, a atividade material humana não pode ser conceituada em abstração ao espaço físico. Mas na medida em que o espaço da atividade humana é inseparável dos eventos e objetos materiais que constituem aquela atividade, o conceito absoluto era incapaz de definir este espaço "social", uma vez que ele era completamente independente dos fenômenos materiais. [...] A separação do espaço relativo e do espaço absoluto ofereceu os meios pelos quais um espaço social poderia ser separado do espaço físico, sendo o espaço social definido não em relação a uma natureza primeira, independente e exterior, mas a uma segunda natureza humanamente produzida. (SMITH, 1988, p. 114 e 115)

\footnotetext{
${ }^{11}$ São apenas trocadilhos, com a tradução de homo erectus e homo sapiens, duas espécies de hominídeos; além de um trocadilho com a definição aristotélica de que o homem é um animal social (ARISTÓTELES. Política. Tradução do grego, introdução e notas de Mário da Gama Kury. 3. ed. Brasília: UNB, 1997.).
} 
N. Smith chega a essa argumentação após ter descrito uma "pequena" história do espaço. Concluiu ele, como se lê acima, que não há como pensar no espaço construído pelo homem da forma como Newton pensava nesse mesmo espaço. Newton que defendia que o espaço era o vácuo onde toda a matéria estava contida e se movia segundo as Três Leis do Movimento, leis essas propostas no "Principia Mathematica Philosophiae Naturalis", em 1687 esse livro que influenciou e ainda influencia o pensamento ocidental, provavelmente como nenhum outro livro científico (RUSSELL, 2001, p. 268 e 269).

Prosseguindo no raciocínio de Smith. Não se pode, então, proceder desse modo, ou seja, pensar da mesma maneira que Newton, pelo fato de que esse físico inglês separava a matéria do espaço: a matéria estava no espaço e não era o espaço - um raciocínio que acabará derivando numa "certa" teoria espacial:

Como vimos, podemos caracterizar a geografia e a ecologia urbanas convencionais como essencialmente sem espaço, pois se concebe que as relações de localização atuam dentro do espaço - isto é, dentro de um espaço que age como um receptáculo, pressuposto mais frequentemente como uma planície sem características próprias. (GOTTDIENER, 1993, p. 125)

Por outro lado, o espaço construído (que Smith chama "social") é a própria matéria em conjunção com a forma; e na configuração em que ela se encontra; o que é basicamente aquilo que Lefebvre quer significar quando diz: "[...] Usa-se espaço exatamente como se usa uma máquina” (LEFEBVRE, $1979^{12}$ apud GOTTDIENER, 1993, p. 128). Colocado assim, Newton, certamente, diria que esse "social" não se trata de espaço.

O espaço ou é relativo, ou absoluto, por um lado; e concreto ou abstrato, por outro lado. Essa distinção se faz necessária uma vez que, ao longo do capítulo 3 ("A Produção do Espaço“) de seu livro, N. Smith utiliza esse par de dicotomias, incessantemente. A certa altura o autor lança a seguinte afirmação:

\footnotetext{
12 LEFEBVRE, H. Space: social product and use value. In: FREIBERG, J. (ed.). Critical Sociology: european perspective. New York: Irvington Publishers, 1979.
} 
"Na medida em que nos ativermos ao processo concreto do trabalho, nossa concepção de espaço será essencialmente absoluta." (SMITH, 1988, p. 129). Lançada essa afirmação surge a questão de sabermos ao que ele está se referindo; pois o autor, simplesmente, faz a mesma afirmação, de chofre, sem esclarecimentos anteriores.

Quero tentar interpretar o sentido do que N. Smith afirmou. Portanto, devo começar pela dicotomia abstrato/concreto - que é a mais simples. Dizer que o espaço é concreto, equivale a dizer que não existe o espaço sem a matéria; caso contrário, ele é uma mera abstração ${ }^{13}$. Se a intenção fosse pensar no trabalho, o sentido dessa dicotomia seria diverso: trabalho concreto é o trabalho socialmente gasto para produzir uma mercadoria qualquer; enquanto que 0 trabalho abstrato é a razão de todo o valor agregado pelas mercadorias produzidas, ou seja, é o trabalho médio, o numéraire (HUNT, 1989). Assim, não existe correspondência necessária entre a aplicação dessas dicotomias, sucessivamente, aos conceitos de espaço e de trabalho.

O sentido da outra dicotomia é mais complicado. Dizer que algo é absoluto, equivale dizer que ele não depende de nenhuma outra coisa; ao mesmo tempo, aquelas coisas que não o são, dependem do que é absoluto. As categorias, por exemplo, são conceitos absolutos:

Così uomo è un concetto inferiore rispetto a essere sensibile, che, come concetto superiore, include oltre agli esseri sensibili razionali, quelli privi di ragione. Questa ascesa progressiva porta ai concetti superiori ultimi, che non stanno più al di sotto di concetti più alti che li unifichino, e perciò si chiamano concetti primi. Questi concetti, originariamente molteplici e distinti, sono le Categorie o generi supremi. ${ }^{14}$

\footnotetext{
${ }^{13}$ É importante acentuar que não há contradição entre a teoria de Newton e a de Smith, pois o espaço concreto é complementar ao abstrato; embora Newton, certamente, não chamaria esse mesmo de espaço concreto, mas de matéria.

14 "Assim, homem é um conceito inferior em relação ao ser sensível, que, como conceito superior, inclui além dos seres sensíveis racionais, aqueles privados de razão. Esse agrupamento progressivo leva aos conceitos superiores últimos, que já não estão sob conceitos mais altos que os unifiquem e por isso os chamamos conceitos primos. Esses conceitos, originariamente múltiplos e distintos, são as Categorias ou gêneros supremos." (Dizionario di Filosofia [traduzione italiana di V. Mathieu e V. Verra dell'opera originale: Philosophisches Wörterbuch; Verlag Herder - Freiburg]; Torino: Editrice Marietti, 1959, p. 61). [Trad. do autor]
} 
Ora, o espaço absoluto (da física newtoniana) é considerado, por Kant, justamente Categoria, ou, mais precisamente, "uma categoria da realidade". Neste sentido, tudo o que possui existência está contido nele e ele não está contido em nenhuma outra coisa (pré) existente:

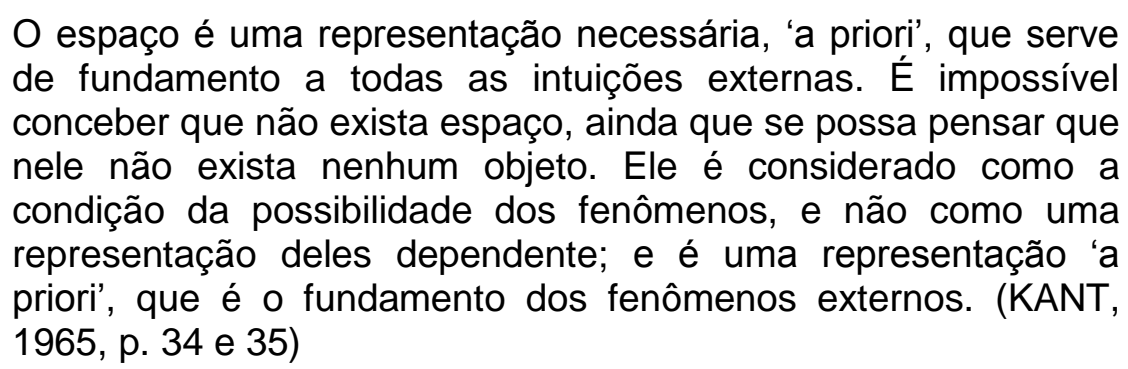

Essa é a mais tradicional noção de espaço, ou seja, de que ele é absoluto. Assim, como foi dito no início deste capítulo, muitas são as noções de espaço, mas: "[...] o que se observou de comum entre as diversas correntes de pensamento" [na filosofia em geral] "foi a noção de espaço como receptáculo e, portanto, condição a priori do fenomênico." (D. SANTOS, 2002, p.188). O espaço como lócus onde todas as entidades e todos os fatos, têm origem e fim.

O espaço relativo, por outro lado, é aquele que depende de outros fatores; que é produzido segundo circunstâncias específicas. Talvez o tempo seja o principal desses fatores condicionantes (e, para entendermos aquela frase hermética da p. 129, do livro de N. Smith) devemos conceber que o tempo impõe sua "potência" sobre o espaço ou, simplesmente, determina o mesmo. Por isso podermos dizer que o Espaço Geográfico ("social") é relativo e concreto: é concreto porque é feito pelo trabalho humano - e esse trabalho ainda não consegue usar o vazio (ou o espírito) como matéria-prima. É, por outro lado, relativo porque se modifica tanto historicamente, quanto sócioculturalmente.

Podemos, agora, entender com mais propriedade a frase de N. Smith. Consideremos o tempo histórico. Consideremos que todas as sociedades têm história; ou melhor, que têm alguma forma de desenvolvimento, alguma mudança ao longo do tempo. Porém, essa história é mais ou menos lenta, de acordo com a sociedade considerada. As sociedades mais primitivas são, por esse motivo, ditas pré-históricas e são objeto, não da Ciência da História, mas 
da Etnologia. O fato de que elas (praticamente) não se modifiquem ao longo do tempo (cronológico) serve de explicação (segundo uma teoria mais tradicional) para que elas não tenham sua história considerada para fins de estudo (sobre mudanças). Nesse sentido, se elas não mudam, seu espaço construído pode ser considerado como ocupando um valor mais próximo do espaço absoluto, num gradiente (teórico) que vai do relativo ao absoluto. E essa análise poderia se aprofundar mais, se tivermos em mente que, numa mesma sociedade, existem vários "seguimentos de duração", ou melhor, linhas de história de diferentes velocidades: umas histórias lentas e outras rápidas (BURKE, 1991).

Voltando, nunc demum, à "pequena" história do espaço, de N. Smith, para depois utilizar essa noção de espaço social absoluto, podemos apontar mais um equívoco desse autor. Vejamos essa passagem:

$\mathrm{Na}$ prática, a sociedade teve que ser separada da natureza antes que o espaço social pudesse ser completamente distinguido do espaço físico. Esse espaço físico absoluto foi associado ao espaço natural da primeira natureza; aqui o espaço natural e o espaço físico são indistinguíveis. (SMITH, 1988, p. 119).

A falha reside no fato de que esse espaço natural não existe (em si), porque ele é a matéria que ocupa lugar no espaço, não importa qual a função dessa matéria - na citação de Kant (KANT, 1965, p. 34 e 35), feita aqui um pouco antes, ele é um fenômeno externo. Para Newton (em "Principia Mathematica Philosophiae Naturalis"), tanto faria se fosse uma maçã ou uma bola de sinuca que caísse em sua cabeça (apesar de um objeto ser natural e o outro social, ambos são igualmente matéria). Assim então, mesmo que a sociedade tenha sido separada (conceitualmente) da natureza, isso não resulta, ontologicamente, no estudo do espaço social, de um lado, e no estudo do espaço físico, de outro. O ideal de um espaço físico absoluto é, ele mesmo, conflitante com o espaço físico relativo. É o conflito entre Newton e os antigos físicos gregos, que o próprio N. Smith apontou (1988, p. 113).

O que devemos ter em conta, para não perdermos o foco do raciocínio, é que ocorreram divisões do trabalho acadêmico - por motivos que aqui não vêm ao caso - e que coube às ciências humanas estudar o espaço "social". 
Espaço esse entendido como algo além da natureza (essa, por sua vez, na acepção ideológica de que trata o primeiro capítulo do livro de Smith). 0 espaço "social" como um todo, é relativo, mas composto por espaços absolutos (na acepção de espaços sem história). Com o advento do Estado Nacional, ocorre um fato muito estranho e novo: tendo em mente que as mudanças numa sociedade qualquer ocorrem por difusão ou por inovação (BOAS, 1966) e que numa sociedade onde há, com freqüência, o excedente econômico é que se verificam a maior parte das inovações, e tendo em mente que essas mudanças é que vão caracterizar a relatividade (chamemos: historicidade) dos espaços "sociais", imaginemos a ação combinada e organizada desses dois elementos modificadores. Essa ação, cujo intuito é gerar mais excedente para que haja mais inovação e difusão, as quais passaram a ser, como se disse, controladas, ou seja, essa ação que é uma espécie de "bola de neve", é o Estado; e ele é abstrato (SMITH, 1988, p. 124-127).

As coisas são dessa forma, porque foram construídas dessa forma, ao longo da história. É como diz N. Smith (1988, p. 130): "Não é Einstein, nem a física, nem a filosofia que, em última instância determina a relatividade do espaço geográfico, mas é o processo atual de acumulação de capital." Essa é uma demonstração da eficiência metodológica do Materialismo Histórico.

A prospecção que N. Smith fez, na definição do Espaço Geográfico, serviu para demonstrar que esse espaço é diferente daquele outro, meramente "social" e que seu surgimento liga-se ao surgimento do Estado Nacional. Esse último, por sua vez, organiza espaços concretos (que Smith denomina, também, de absolutos, mas isso é meio metafórico) em seu interior, onde eram realizados trabalhos concretos. A universalização do trabalho abstrato e a conseqüente universalização do valor-de-troca são possíveis com o advento do Espaço Geográfico, tum demum. (SMITH, 1988, p. 130). Ora, é uma tendência do desenvolvimento capitalista a utilização cada vez menor de mão-de-obra, na composição orgânica do capital. Marx chamava a atenção para isso. Dizia que a mais-valia relativa estava se tornando a principal fonte de valor: 
jornada de trabalho durante a qual o trabalhador tem de trabalhar para si mesmo, justamente para prolongar a outra parte da jornada do trabalho durante a qual pode trabalhar gratuitamente para o capitalista. Até que ponto pode-se alcançar ainda esse resultado sem baratear as mercadorias, mostrar-se-á nos métodos particulares de produção da maisvalia relativa, [...]. (MARX, 1996, p. 437)

Senão vejamos: o trabalho necessário é aquele que reproduz o valortrabalho e o trabalho excedente é o lucro capitalista (medido em trabalho abstrato). A diferença entre o trabalho (efetivo) e o trabalho necessário é a fonte da mais-valia porque, para sua própria manutenção, o trabalhador necessita de muito menos valor do que o seu trabalho gera efetivamente (ainda mais, com o auxílio do capital fixo). Se para David Ricardo a tendência decrescente da taxa de lucro se explicava pelo crescimento das necessidades agrícolas em relação a um solo sempre mais pobre e, assim, mais caro, para Marx a mesma tendência era explicada pelo aumento da composição orgânica do capital: como é o capital variável que gera a mais-valia, sua substituição por capital constante - ou seja, uma tendência à mais-valia relativa - derrubaria a taxa de lucro. (HUNT, 1989).

Se o espaço entra como um fator de produção, certamente não faz parte do capital variável, mas do constante. A logística prova a importância que o espaço adquiriu na produção (SMITH, 1988, p. 137 e 138) e adquiriu essa importância na proporção inversa do valor-trabalho, ou seja, conjuga-se àquela idéia (ou ideologia) de corte dos custos; o qual é a única maneira que os capitalistas têm encontrado para manter uma taxa de lucro mínima.

Podemos agora finalizar esse texto, apontando como esse Espaço Geográfico é produzido desigualmente. Na verdade é essa a questão apontada no título do livro de N. Smith.

Pois bem! Para além da queda da taxa de lucro, outra tendência do capitalismo é a equalização dessas mesmas taxas de lucro (sempre em queda) através dos vários setores da economia. Na verdade, deveríamos dizer: os vários empreendimentos, o que significa que as empresas terão taxas de lucro mais ou menos iguais, porque, quando migra de um empreendimento para o outro, o capital nivela (por baixo) as taxas de lucro - isso tudo pode ser dito, 
evidentemente, pautando-se na teoria marxiana (MARX, 1996). Ocorre que esses empreendimentos, na prática, nunca terão a mesma composição orgânica de capital porque o capital variável é determinado por uma divisão do trabalho (social) que vai além da divisão que ocorre na fábrica, além da divisão entre o que cabe a cada fábrica fazer e, ainda, além da divisão entre setores (primário, secundário etc). É duma divisão internacional, que separa os países pobres dos ricos, que devemos lançar mão.

A especialização das atividades (no âmbito do capitalismo, tido como Modo de Produção global por natureza ${ }^{15}$ ) sempre vai gerar a especificação locacional das mesmas (o que denominamos, eventualmente, de "o endereço"). Essa especificação já foi considerada praticamente natural - na forma de "vantagens comparativas", por exemplo, pela teoria ricardiana ${ }^{16}$ - e, a partir dum certo momento histórico, passou a ser tomada como estritamente social (SMITH, 1988, p. 152 e 153). Pois, quando o capitalismo alcança seu estágio superior (Imperialismo), ele passa a gerir e reproduzir uma divisão que ele mesmo criou, historicamente, em conseqüência do seu longo trajeto de construção da dependência entre as áreas periféricas e as áreas centrais, onde o capital esteve concentrado. Então ele (o capital trustificado) pode abandonar essa área central cara (em termos, sobretudo, de capital variável) e migrar para aquelas onde muito capital constante ainda poderá ser "injetado"; em outras palavras: onde ainda será possível realizar a Concentração de Capital.

Nesse processo, o capitalismo produz e reproduz constantemente a riqueza, pari passu, a escassez, para se beneficiar de ambas, em momentos sucessivos. Riqueza e escassez que, por seu turno, são manifestadas espacialmente em centros e periferias; os dois (espaços) relativos e concretos.

\footnotetext{
15 Segundo a "Teoria do Sistema Mundo", que é uma decorrência lógica e cronológica da "Teoria da Dependência". O principal autor daquela teoria, Wallerstein sempre se negou a adotar o conceito de Terceiro Mundo (estudioso que foi da África pós-Colonial), argumentando que existe apenas um único mundo, o qual é articulado por um sistema de trocas econômicas, ou seja, uma economia mundial, onde se destaca a dicotomia entre capital e trabalho.

16 Sua "Teoria das Vantagens Comparativas" constitui a base essencial das teorias do comércio internacional.
} 


\section{Considerações finais}

Como já fora indicado no início deste texto, o espaço possui um papel significativo no processo de reprodução e reformulação intrínseco, do Modo de Produção Capitalista. Para N. Smith, a existência do Espaço, simultaneamente como fator de produção, mercadoria e assentamento, apresenta os tópicos desse processo que é econômico, como também político.

Entretanto, sua teoria é abrangente demais (do ponto de vista do método, mas, principalmente, do objeto), sendo muito improvável inexistirem tantas críticas sobre ela. Intenta, nada mais, nada menos, argumentar que o capitalismo sobreviveu ao Séc. XX (e vai sobreviver ainda) através da produção de espaço ${ }^{17}$. Como se não bastasse essa complicada extensão da teoria, ela demonstra ainda muitas exceções à sua regra.

Nas últimas linhas do capítulo anterior, se vinha dizendo que o capital (na sua forma trustificada) move-se do centro para a periferia do sistema (agora) mundial. Faltou discorrer mais sobre o fato de que, após ocorrido esse evento, o centro se desvaloriza, enquanto a periferia inflaciona-se; o que promove o retorno do capital ao centro - isso é o que Smith denomina: vaivém do capital; provavelmente, baseado na idéia dos três Circuitos de Capital de Harvey (GOTTDIENER, 1993, p. 101-103). Mas, esse vaivém não é empiricamente comprovado em duas das três escalas estudadas por Smith (1988), quais sejam: do Estado-nação e a internacional. Somente na escala intra-urbana se verifica esse vaivém, ou seja, o capital saiu do centro, foi para a periferia e voltou para o centro, de novo. Isso o próprio Smith reconhece (1988, p. 215 e 216$)$.

De qualquer forma, essa teoria de Smith, possui muitos elementos ao seu favor, como por exemplo, o comportamento cíclico do mercado imobiliário, ao longo de "ondas" especulativas - as quais correspondem às crises de investimento no Circuito Primário. Motivo pelo qual, enfim, consideremos que ela (a teoria de Smith) responde às questões aqui levantadas, acerca da simbiose entre reprodução capitalista e Produção do Espaço.

\footnotetext{
${ }^{17}$ Essa é outra proposição de Harvey, na introdução do livro de Smith (1988); na página 25.
} 
Enquanto que a questão de ser a natureza produzida ou não, esbarra no conceito (ainda recalcitrante) de espaço; sobretudo na discrepância entre o conteúdo desse conceito em relação ao conteúdo do conceito de natureza.

Entre os teóricos envolvidos nesse debate, Milton Santos (2002) fala em Meio Técnico: escreve que o espaço é um sistema de objetos e de ações no qual a natureza "diminui" na proporção inversa da intencionalidade, ou seja, quanto mais intencionalidade, menos natureza. Aliás, pela reserva que Milton faz à intencionalidade - de quem, ou de qual grupo (ou qual classe etc), na prática, ela parte -, ele se alinha ao Marcuse; o qual, como dito no começo deste texto, alerta para o domínio do homem pelo homem como se fosse um domínio da natureza pelo homem. Mas a questão está longe de ser solucionada e, talvez, nunca o seja.

De todo modo, outros argumentos de N. Smith poderiam ter sido analisados ou os argumentos citados analisados com maior profundidade para que dessem margem a outras reflexões. Talvez, com mais fôlego (posto que o presente texto é de pequeno alcance), eu possa realizar essa tarefa, futuramente. Importante é reconhecer a qualidade desse livro e, naturalmente, de seu autor: Neil Smith - uma vez que, a dureza das críticas pode ter causado a impressão contrária. Aliás, não foram as críticas que consegui (sob muita reflexão) fazer que vão minorar a importância desse livro. O próprio David Harvey (SMITH, 1988, p. 26) já alertara que "uma contribuição dessa natureza certamente provocará controvérsias e críticas".

Por fim, é necessário que eu reconheça que é muito mais simples essa minha atividade de fazer a crítica, em comparação com a pesquisa e a construção da teoria exposta no livro de Smith. Assim, reconheço igualmente a função do meu texto, mas se o faço, é com orgulho e não com desapontamento; posto que essa crítica tem por objetivo acrescentar à pesquisa, como um todo, ou melhor, fortalecê-la. Nunca é desnecessário repetir aquele bordão segundo o qual (na ciência) as perguntas valem mais do que as respostas.

Eu diria, também, que me sinto próximo a Smith (guardadas as devidas proporções) e de tantos outros (anônimos como eu, ou não) que pensaram a 
sociedade com sobriedade crítica - o que significa dizer que não me enfileiro junto dos sectários do chamado marxismo, seja ortodoxo, revisionário etc; ou de quaisquer outros sectários. O mundo real aponta (ainda) para a existência da exploração de uma classe por outra; ignorar isso é um sinal de ignorância ou de má-fé. Porém, nos encastelarmos em nossos "departamentos", em nossas "linhas de pesquisa" não nos permite julgar melhor ou agir melhor sobre esse mundo. Aliás, "encastelar-se" é reproduzir o status quo, a exploração, o domínio (do homem pelo homem). Acredito ser mais importante construirmos pontes do que muralhas.

\section{Referências bibliográficas}

ABRAMOVAY, R. Paradigmas do capitalismo agrário em questão. 3. ed. São Paulo: Edusp, 2007.

ARANTES, P. E. Benjamin, Horkheimer, Adorno, Habermas - Vida e obra; Cronologia; Bibibliografia. In: Textos Escolhidos de Walter Benjamin, Max Horkheimer, Theodor Adorno, Jürgen Habermas. Trad. José Lino Grünnewald [et al.]. São Paulo: Abril Cultural, 1980.

BERGER, P. L. \& LUCKMANN, T. A Construção Social da Realidade. Trad. Floriano de Souza Fernandes. 2. ed. Petrópolis: Vozes, 1974.

BLAKE, W. Proverbs of hell; Plate 11. In: The Marriage of Heaven and Hell. Classic Poetry Series. PoemHunter.com, 2004.

BOAS, F. Early cultural traits. In: The Mind of Primitive Man. 2. ed. New York: The Macmillan Company (A Free Press Paperback), 1966.

BURKE, P. A Revolução Francesa da historiografia: a Escola dos Annales (1929-1989). Trad. Nilo Odália. São Paulo, Editora UNESP, 1991.

DOSSE, F. História do estruturalismo. Trad. Álvaro Cabral. São Paulo: Ensaio; Campinas: Editora da Unicamp, 1993.

GONÇALVES, C. W. P. Os (Des)caminhos do Meio Ambiente. 6. ed. São Paulo: Contexto, 1998

GOTTDIENER, M. A Produção Social do Espaço Urbano. Trad. Geraldo Gerson de Souza. São Paulo: EDUSP, 1993. 
HABERMAS, J. Técnica e ciência enquanto ideologia. In: Textos Escolhidos de Walter Benjamin, Max Horkheimer, Theodor Adorno, Jürgen Habermas. Trad. Željko Loparić e Andréa Maria Altino de Campos Loparić. São Paulo: Abril Cultural, 1980.

HUNT, E. K. História do Pensamento Econômico. Trad. José Ricardo Brandão Azevedo. 7. ed. Rio de Janeiro: Campus, 1989.

KANT, I. Crítica da Razão Pura. Trad. J. Rodrigues de Mereje. 4. ed. São Paulo: Ed. Pub. Brasil, 1965.

MARX, K. O capital: crítica da economia política. Vol. 1. Apresent. Jacob Gorender. Coord. Rev. Paul Singer. Trad. Regis Barbosa e Flávio R. Kothe. Coleção Os Economistas. São Paulo: Nova Cultural, 1996.

RÜSEN, J. Razão histórica - teoria da história: fundamentos da ciência histórica. Trad. Estevão de Rezende Martins. Brasília: Editora Universidade de Brasília, 2010.

RUSSELL, B. História do Pensamento Ocidental. Trad. Laura Alves e Aurélio Rebello. Rio de Janeiro: Ediouro, 2001.

SANTOS, D. A Reinvenção do Espaço. São Paulo: Editora UNESP, 2002.

SANTOS. M. A Natureza do Espaço. São Paulo: EDUSP, 2002.

SMITH, N. Desenvolvimento Desigual: natureza, capital e a produção do espaço. Trad. Eduardo de Almeida Navarro. Rio de Janeiro: Bertrand Brasil, 1988.

VAZ, H. C. L. Antropologia filosófica. 2. Vol. São Paulo: Loyola, 1992. 